\title{
Serum Sialic Acid Concentration and Atherosclerotic Risk Factors
}

\author{
Ichiro Wakabayashi', Kunihiro Sakamoto', Sachiko Yoshimoto', and Eizo Kakishita² \\ ${ }^{1}$ Department of Hygiene and ${ }^{2}$ Second Department of Internal Medicine, Hyogo College of Medicine, Hyogo, Japan.
}

\begin{abstract}
To clarify the significance of increased blood sialic acid in atherosclerotic cardiovascular disease, we investigated the relationship between serum sialic acid level and atherosclerotic risk factors such as serum uric acid, fasting blood glucose, systolic and diastolic blood pressure, atherogenic index, and white blood cell count. By simple regression analysis, the serum sialic acid level was found to correlate significantly with these parameters. The mean sialic acid level was significantly higher in the highest quartile for serum uric acid than in its lowest quartile and also for fasting blood glucose concentration in comparison with its other three quartiles. A tendency was noted for the mean serum sialic acid level of each quartile to become higher with an increase in the quartiles of systolic or diastolic blood pressure, atherogenic index, and white blood cell count. Multiple regression analysis showed the correlations to be significant for the relationship of serum sialic acid to atherogenic index, mean arterial pressure and white blood cell count. From these results and previous findings of higher serum sialic acid levels in smokers, patients with diabetic angiopathies, and patients with hyperlipidemia, it is suggested that serum sialic acid reflects the degree of atherosclerotic progress involving inflammation processes. $J$ Atheroscler Thromb, 1994 ; 1 : 113-117.
\end{abstract}

Key words : Atherosclerosis, Diabetes Mellitus, Hypertension

Sialic acid, a component of glycoprotein, lipoprotein and glycolipid, is present in acute-phase reactants (e.g. $\alpha_{1}$-acid mucoprotein, $\alpha_{1}$-antitrypsin, ceruloplasmin and fibrinogen), which are produced in the liver in response to triggers such as tissue damage occurring in inflammatory diseases and malignancy. Thus, serum sialic acid is measured to screen for inflammatory and malignant diseases and to follow their clinical courses.

A recent prospective study by Lindberg et al.(1) revealed that the serum sialic acid concentration can be a strong predictor of high mortality from cardiovascular disease. Also, increased serum sialic acid concentrations have been found in smokers (2), patients with diabetic angiopathies (3) and patients with hyperlipidemia $(4,5)$. These findings suggest that an increase in serum sialic acid may reflect the progress of atherosclerosis, since diabetes mellitus, hyperlipidemia and smoking are all risk

Address for correspondence: Ichiro Wakabayashi, Department of Hygiene, Hyogo College of Medicine, 1-1 Mukogawa-cho, Nishinomiya, Hyogo 663, Japan.

Received February 25, 1994.

Accepted for publication June 24, 1994 factors for atherosclerotic cardiovascular diseases. However, there have been few studies of the relationship between serum sialic acid level and various atherosclerotic risk factors, and the putative causal relationship between atherosclerosis and increased serum sialic acid remains to be clarified. This led us to investigate whether the serum sialic acid concentration shows an association with such atherosclerotic risk factors as serum uric acid, fasting blood glucose, blood pressure and white blood cell count, which are frequently evaluated in general health examinations. We also evaluated the correlations between serum sialic acid and the items constituting atherosclerotic risk factors, including serum lipids.

\section{Methods}

\section{Subjects and blood sampling}

The subjects were 382 men, aged 35-54 years old, who were employed in a printing company, including both clerks and factory workers. They participated in a periodic medical health examination at their workplace; the 
response rate was $98 \%$. The age distribution of the subjects was as follows : $18.1 \%, 35-39$ years old ; $20.9 \%$, $40-44$ years old; $38.2 \%$, $45-49$ years old; and $22.8 \%$, 50-54 years old. The subjects had neither histories of cardiovascular disease nor symptoms of infection on the morning of the examination. Blood was sampled between $9 \mathrm{am}$ and noon after the subjects had fasted overnight. Besides serum, a portion of each blood sample was collected into tubes containing sodium fluoride for glucose measurement or EDTA for determining white blood cell counts.

\section{Measurements}

Serum lipid (triglyceride, total cholesterol, HDL-cholesterol), uric acid and blood glucose were enzymatically measured with an automatic analyzer. White blood cells were counted with a Coulter Counter.

Serum sialic acid concentration was assayed by an enzymatic method (6) using a kit (Ultrate - SIA) obtained from Toyobo Co., Ltd. In brief, $1.5 \mathrm{ml}$ of reagent A containing $0.435 \mathrm{mg} \mathrm{NADH}$ and $3.0 \mathrm{U}$ lactate dehydrogenase was added to $50 \mu$ l of each serum sample, the standard of sialic acid and a blank (distilled water). After $3 \mathrm{~min}$ incubation at $37^{\circ} \mathrm{C}$, reagent $\mathrm{B}$ containing $5.7 \mathrm{U} \mathrm{N}$-acetylneuraminic acid aldolase and $0.3 \mathrm{U}$ neuraminidase was added to each mixture and incubated at $37^{\circ} \mathrm{C}$ for $1.5 \mathrm{~min}$. Next, the absorbance (A) at $340 \mathrm{~nm}$ of each mixture was measured, and sialic acid concentration was calculated as :

$$
\left[\left(\mathrm{A}_{\text {sample }}-\mathrm{A}_{\text {blank }}\right) /\left(\mathrm{A}_{\text {standard }}-\mathrm{A}_{\text {blank }}\right)\right] \times \text { standard }
$$

concentration

The above process was adapted for use with a Hitachi 736 autoanalyzer. The coefficient of variation between batch assays was $3.0 \%$.

The atherogenic index was calculated as: (total cholesterol-HDL cholesterol)/HDL cholesterol. After each subject had sat resting quietly for five minutes, blood pressure was recorded with a random zero sphygmo manometer; Korotkoff phase $\mathrm{V}$ was used to define diastolic pressure. Mean arterial pressure (MAP) was calculated as : $\mathrm{MAP}=$ diastolic blood pressure $+1 / 3 \times($ systolic blood pressure-diastolic blood pressure).

\section{Statistical analysis}

The data distribution pattern was evaluated using normal probability paper and showed almost linear plots for each parameter. Thus, the data from all of the atherosclerotic risk factors and serum sialic acid displayed a normal distribution. The values for each variable (uric acid, fasting blood glucose, systolic blood pressure, diastolic blood pressure, atherogenic index, white blood cell count) were arranged in ascending order and then the subjects were divided into four groups of approximately equal size. In this study, the range of values for each risk factor was relatively narrow, and the subjects were divided into four relatively large sections (quartiles). Mean concentrations of serum sialic acid were compared among the quartiles for each variable. Data are expressed as means \pm SD or means \pm SE. Student's $t$-test was used to compare group means. In regression analysis, a simple regression coefficient $(r)$ and a standardized multiple regression coefficient were calculated. Probability (p) values less than 0.05 were defined as significant.

\section{Results}

\section{Mean serum sialic acid levels in quartiles for each athero- sclerotic risk factor}

The overall data of all parameters are given in Table 1. The mean serum sialic acid levels $(\mathrm{mg} / \mathrm{dl}$ ) with SD of each quartile for serum uric acid were $57.3 \pm 10.1$ (1st quartile), $58.3 \pm 8.0$ (2nd quartile), $58.5 \pm 6.6$ (3rd quartile) and $60.3 \pm 6.4$ (4th quartile), and for fasting blood glucose were $57.9 \pm 7.1$ (1st quartile), $58.1 \pm 8.0$ (2nd quartile), $57.7 \pm 6.6$ (3rd quartile) and $60.8 \pm 9.6$ (4th quartile). The mean serum sialic acid levels were lower in the lowest quartile of serum uric acid levels than in the highest quartile (Fig. $1 \mathrm{~A})$, and higher in the highest quartile of fasting blood sugar than those in the other three quartiles (Fig. 1B). The mean serum sialic acid levels $(\mathrm{mg} / \mathrm{dl})$ with SD of each quartile for systolic pressure were $56.5 \pm 7.0$ (1st quartile), $57.1 \pm 7.3$ (2nd quartile), 59.5 \pm 9.5 (3rd quartile) and 61.5 \pm 6.7 (4th quartile), and for diastolic pressure were $56.9 \pm$ 10.3 (1st quartile), $57.8 \pm 7.4$ (2nd quartile), 59.8 \pm 6.4 (3rd quartile) and $60.1 \pm 6.1$ (4th quartile). In the first and second quartiles of systolic or diastolic blood pressure, the mean sialic acid levels were lower than those in the highest quartile (Figs. 1C, D). The mean serum sialic acid levels $(\mathrm{mg} / \mathrm{dl})$ with $\mathrm{SD}$ of each quartile for atherogenic index were $57.0 \pm 8.0$ (1st quartile), $56.9 \pm 7.2$ (2nd quartile), $59.0 \pm 6.2$ (3rd quartile) and $61.5 \pm 9.3$ (4th quartile), and for white blood cell count were $55.7 \pm 6.5$ (1st quartile), $57.9 \pm 6.4$ (2nd quartile), 58.0 \pm 6.3 (3rd quartile) and $62.8 \pm 10.2$ (4th quartile). The mean serum sialic acid level in the highest quartile of atherogenic index or white blood cell count was higher than in the other quartiles (Figs. 1E, F).

The mean serum sialic acid level of each quartile of age was $57.0 \pm 6.8 \mathrm{mg} / \mathrm{dl}$ (1st quartile), $59.2 \pm 7.1 \mathrm{mg} / \mathrm{dl}$ (2nd quartile), $59.2 \pm 9.7 \mathrm{mg} / \mathrm{dl}$ (3rd quartile) and $58.7 \pm 7.5 \mathrm{mg} /$

Table 1. Parameters of the subjects.

\begin{tabular}{lc}
\hline & Mean \pm SD \\
\hline Serum uric acid $(\mathrm{mg} / \mathrm{dl})$ & $5.01 \pm 1.24$ \\
Fasting blood sugar $(\mathrm{mg} / \mathrm{dl})$ & $98.9 \pm 15.2$ \\
Systolic blood pressure $(\mathrm{mmHg})$ & $122 \pm 16$ \\
Diastolic blood pressure $(\mathrm{mmHg})$ & $79.5 \pm 10.8$ \\
White blood cell count $\left(/ \mathrm{mm}^{3}\right)$ & $6142 \pm 1845$ \\
Atherogenic index & $2.67 \pm 1.22$ \\
Serum sialic acid $(\mathrm{mg} / \mathrm{dl})$ & $58.6 \pm 7.9$ \\
\hline
\end{tabular}



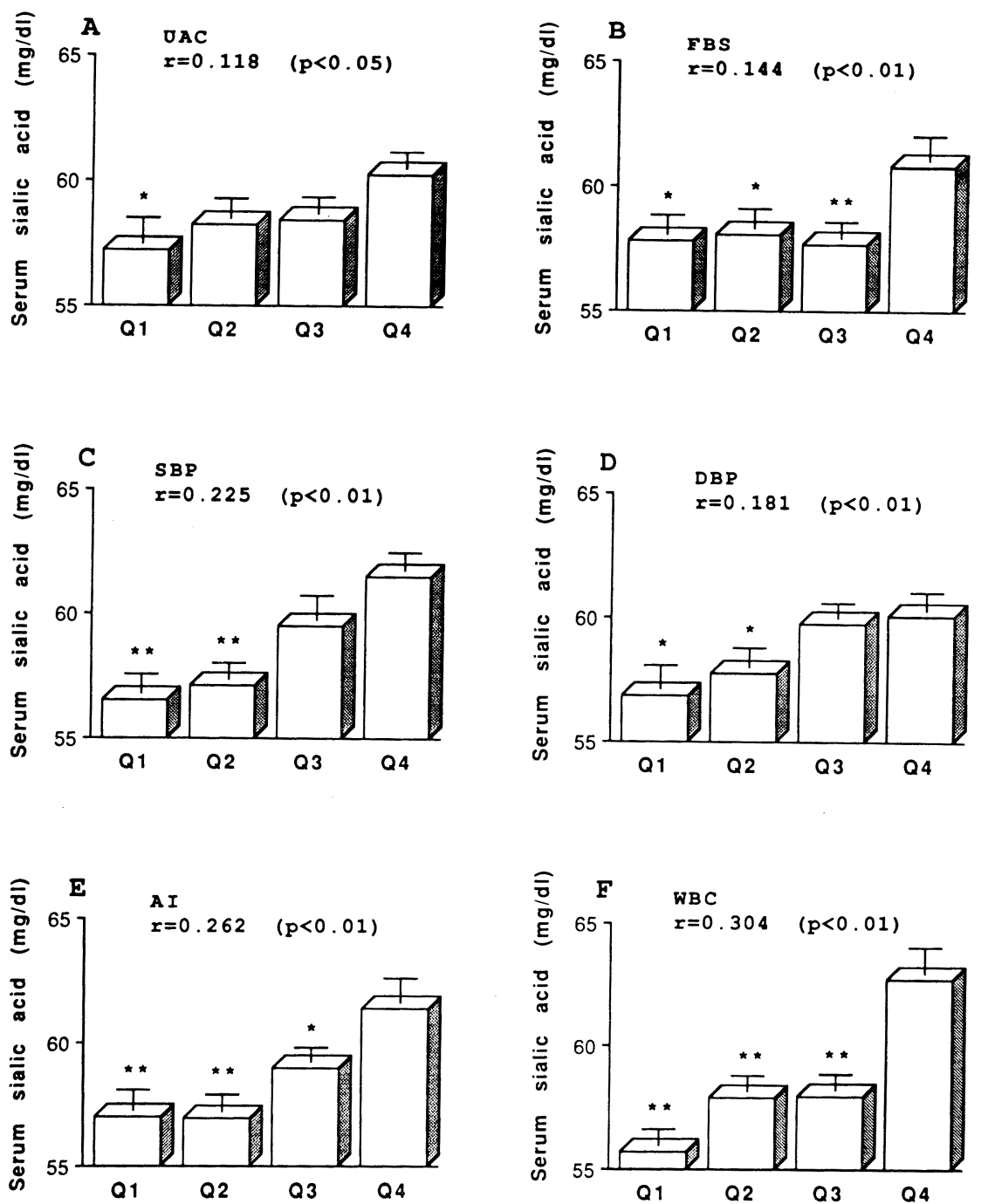

Fig. 1. (A) Serum sialic acid concentrations in quartiles of serum uric acid level (UAC, $\mathrm{mg}$ / $\mathrm{dl}$ ), and simple correlation coefficient (r) between serum sialic acid and uric acid concentrations. Bars indicate SE and an asterisk denotes significant difference from the value of Q4 $(\star=p<0.05)$. (B) Serum sialic acid concentrations in quartiles of fasting blood glucose (FBS, $\mathrm{mg} / \mathrm{dl}$ ), and simple correlation coefficient ( $\mathrm{r}$ ) between serum sialic acid and fasting blood glucose concentrations. Bars indicate SE and asterisks denote significant differences from the value of Q4 ( $\star=p<0.05, \star \star=p<0.01)$. (C) Serum sialic acid concentrations in quartiles of systolic blood pressure (SBP, $\mathrm{mmHg}$ ), and simple correlation coefficient (r) between serum sialic acid concentration and systolic blood pressure. Bars indicate SE and asterisks denote significant differences from the value of $Q 4(\star \star=p<0.01)$. (D) Serum sialic acid concentrations in quartiles of diastolic blood pressure (DBP, $\mathrm{mmHg}$ ), and simple correlation coefficient (r) between serum sialic acid concentration and diastolic blood pressure. Bars indicate SE and asterisks denote significant differences from the value of Q4 $(\star=p<0.05)$. (E) Serum sialic acid concentrations in quartiles of atherogenic index (Al), and simple correlation coefficient $(r)$ between serum sialic acid concentration and atherogenic index. Bars indicate $\mathrm{SE}$ and asterisks denote significant differences from the value of Q4 $(\star=p<0.05, \star \star=p<$ 0.01). (F) Serum sialic acid concentrations in quartiles of white blood cell count (WBC, per $\mathrm{mm}^{3}$ ), and simple correlation coefficient $(\mathrm{r})$ between serum sialic acid concentration and white blood cell count. Bars indicate SE and asterisks denote significant differences from the values of $\mathrm{Q} 4(\star \star=p<0.01)$. 
dl (4th quartile). No significant difference was found in the serum sialic acid levels among the age quartiles.

\section{Correlations between serum sialic acid levels and athero- sclerotic risk factors}

Simple correlation coefficients were significant for the serum sialic acid level in relation to serum uric acid level, fasting blood sugar, systolic and diastolic blood pressure, atherogenic index and white blood cell count (Fig.1). Atherogenic index and white blood cell count showed relatively strong correlations with serum sialic acid $(r=$ 0.262 and 0.304 , respectively). The simple correlation coefficient between age and serum sialic acid was not significant $(r=0.055)$.

Table 2. Standardized multiple regression coefficients and statistical significance between serum sialic acid and variables of atherosclerotic risk factors.

\begin{tabular}{lcc}
\hline & $\begin{array}{c}\text { Standardized } \\
\text { coefficient }\end{array}$ & $\begin{array}{c}\text { Statistical } \\
\text { significance }\end{array}$ \\
\hline Age & 0.085 & $\mathrm{NS}$ \\
Serum uric acid & 0.065 & $\mathrm{NS}$ \\
Fasting blood sugar & 0.089 & $\mathrm{NS}$ \\
Mean arterial pressure & 0.124 & $\mathrm{p}<0.05$ \\
Atherogenic index & 0.159 & $\mathrm{p}<0.01$ \\
White blood cell count & 0.265 & $\mathrm{p}<0.01$ \\
\hline
\end{tabular}

NS, not significant.

As systolic and diastolic blood pressure showed a strong correlation $(r=0.739)$, they were represented as the mean arterial pressure in multiple regression analysis. Serum lipid factors such as total cholesterol, triglyceride and HDL-cholesterol are known to affect each other, and thus the atherogenic index was used as the representative of serum lipid for multiple regression analysis. Consequently, multiple regression analysis was performed with serum sialic acid as the target coefficient and the six items of age, atherogenic index, serum uric acid, fasting blood glucose, mean arterial pressure and white blood cell count as explanation coefficients (Table 2). Significant standardized multiple regression coefficients were obtained for the relationships of serum sialic acid to atherogenic index, mean arterial pressure, and white blood cell count.

\section{Discussion}

Diabetes mellitus, hyperuricemia, hypertension and hyperlipidemia are all known to be risk factors for atherosclerosis. In this study, both simple and multiple regression analysis data showed that blood pressure, atherogenic index and white blood cell count were correlated with the serum sialic acid concentration. Thus, serum sialic acid is clearly associated with blood pressure, serum lipid and white blood cell count in healthy subjects.
On the other hand, serum uric acid and blood glucose showed no significant correlation with serum sialic acid in multiple regression analysis. However, simple correlation coefficients between serum sialic acid and serum uric acid or blood glucose were significant, and mean sialic acid levels in the highest quartiles of serum uric acid and fasting blood glucose concentrations were higher than those in the lowest quartile and the other three lower quartiles, respectively. This suggests that serum sialic acid increases in persons with hyperuricemia and hyperglycemia, and agrees with the previous finding that plasma sialic acid increased in diabetic patients under poor control and with retinopathy, but not in those under good control and without retinopathy (7).

Recently, it has been found that increases in serum sialic acid may predict mortality from atherosclerotic cardiovascular disease (1). However, there have been only a few studies on the relationship between serum sialic acid and atherosclerotic risk factors. Previous studies have shown that atherosclerotic risk factors such as smoking and hyperlipidemia are related to increases in serum sialic acid $(2,4,5)$. In our previous study using the same subjects as in the present study, the serum sialic acid levels were found to be higher in those with higher levels of serum total cholesterol and triglyceride or in those with lower levels of serum HDL-cholesterol (5). In the present study, other risk factors of atherosclerosis, such as systolic and diastolic blood pressure, serum uric acid, and fasting blood glucose, were also significantly correlated with serum sialic acid. We could not evaluate other atherosclerotic risk factors such as obesity, smoking history and blood fibrinogen level. To our knowledge, there have been few Japanese studies on the relation of serum sialic acid and atherosclerotic risk factors, except for diabetes mellitus. In one study by Horie et al., serum sialic acid levels were higher in the smokers and aged subjects (8). Lindberg et al. showed that serum sialic acid concentration is more predictive of mortality from both coronary heart disease and stroke than body mass index and serum total cholesterol, but is less predictive than diastolic blood pressure (9). Thus, increases in serum sialic acid may reflect the degree of atherosclerotic progress involving inflammation processes.

Previous studies have suggested that white blood cell count is a risk factor for ischemic heart disease and cerebral infarction (10-12). In addition, serum sialic acid level as well as white blood cell count increase in association with the acute-phase response. Thus, both serum sialic acid and white blood cell count seem to be associated with the acute-phase response and the incidence of atherosclerotic cardiovascular diseases. This may explain the present finding that white blood cell count showed the strongest correlation with serum sialic acid level $(r=0.304)$ among the atherosclerotic risk factors evaluated.

Fibrinogen has been found to be a major risk factor for 
ischemic heart disease and stroke (13-15). A recent report has shown a strong correlation between the concentration of orosomucoid, an acute-phase reactant, and the fibrin gel properties (a proneness to the formation of tight, rigid and space-filling fibrin network structures) in plasma from patients with old myocardial infarction (16). Furthermore, a strong positive correlation between plasma fibrinogen and serum sialic acid has recently been found in healthy subjects (17). Inasmuch as fibrinogen is an acute-phase reactant and contains sialic acid, elevation of the serum sialic acid concentration in atherosclerosis may reflect, in part, an increase in blood fibrinogen. Thus, increased serum sialic acid levels in cardiovascular disease may be due to an acute-phase protein response involved in atherosclerosis.

In this study, no significant relationship was found between age and serum sialic acid level. However, Lindberg et al. suggested that serum sialic acid levels increase with age (1). This discrepancy may have been due to differences in subject age distributions; the age distribution of our subjects (35 54 years old) was narrower than those examined by Lindberg et al. $(25 \sim 74$ years old).

We conclude that serum sialic acid is significantly related to risk factors for atherosclerosis and may reflect the degree of atherosclerotic progress. Further studies are required to elucidate whether serum sialic acid can be used as a good marker of atherosclerosis.

Acknowledgement: The authors are grateful to Mrs. Judy Noguchi for her assistance in the preparation of the manuscript.

\section{References}

(1) Lindberg G, Eklund GA, Gullberg B, and Råstam L: Serum sialic acid concentration and cardiovascular mortality. Br Med J, 302 : 143-146, 1991

(2) Lindberg G, Raståm L, Gullberg B, Eklund GA, and Törnberg $S$ : Serum sialic acid concentration and smoking: a population based study. Br Med J, 303: 13061307, 1991

(3) Shvartz LS and Paukman LI: Diabetic angiopathies and mucopolysaccharide metabolism. Problemy Endokrinologii (Moskva), 17 : 37-41, 1971

(4) Crook $M$ and Tutt $P$ : Serum sialic acid concentration in patients with hypertriglyceridaemia showing the Freder- ickson's IIB phenotype. Clin Sci, 83: 593-595, 1992

(5) Wakabayashi I, Sakamoto K, Yoshimoto S, and Masui H: Relation of serum sialic acid to lipid concentrations. $\mathrm{Br}$ Med J, 305 : 562-563, 1992

(6) Comb DG and Roseman S: The sialic acid. 1. The structure and enzymatic syrithesis of $\mathrm{N}$-acetylneuraminic acid. J Biol Chem, 235 : 2529-2537, 1960

(7) Taniuchi K, Miyamoto Y, Tanaka T, Doi K, and Baba S: Acute phase proteins and platelet sialic acid in diabetic patients. J Japan Diab Soc, 27: 41-49, 1984 (in Japanese)

(8) Horie S, Kudoh T, Hiro N, and Ohkawa H: Significance of serum sialic acids and CRP levels at occupational health check-up. Jap J Ind Health, 31: 582, 1989 (in Japanese)

(9) Lindberg G, Raståm L, Gullberg B, and Eklund GA : Serum sialic acid concentration predicts both coronary heart disease and stroke mortality : multivariate analysis including 54385 men and women during 20.5 years follow-up. Int J Epidemiol, 21: 253-257, 1992

(10) Friedman GD, Klatsky AL, and Siegelaub AB: The leukocyte count as a predictor of myocardial infarction. $N$ Engl J Med, 290 : 1275-1278, 1974

(11) Prentice RL, Szatrowski TP, Kato H, and Mason MW : Leukocyte counts and cerebrovascular disease. J Chron Dis, 35: 703-714, 1982

(12) Kostis JB, Turkevich D, and Sharp J: Association between leukocyte count and the presence and extent of coronary atherosclerosis as determined by coronary arteriography. Am J Cardiol, 53: 997-999, 1984

(13) Meade TW, North WRS, Chakrabarti R, Stirling Y, Haines AP, and Thompson SG: Haemostatic function and cardiovascular death: Early results of a prospective study. Lancet, i : 1050-1053, 1980

(14) Wilhelmsen L, Svärdsudd K, Korsan-Bengtsen K, Larsson $B$, Welin $L$, and Tibblin $G$ : Fibrinogen as a risk factor for stroke and myocardial infarction. N Engl J Med, 311 : 501-505, 1984

(15) Yarnell JWG, Baker IA, Sweetnam PM, Bainton D, O'Brien JR, Whitehead PJ, and Elwood PC : Fibrinogen, viscosity, and white blood cell count are major risk factors for ischemic heart disease: The Caerphilly and Speedwell collaborative heart disease studies. Circulation, 83: 836-844, 1991

(16) Fatah K, Hamsten A, Blombäck B, and Blombäck $M$ : Fibrin gel network characteristics and coronary heart disease: Relations to plasma fibrinogen concentration, acute phase protein, serum lipoproteins and coronary atherosclerosis. Thromb Haemost, 68 : 130-135, 1992

(17) Kario K and Matsuo T: Relation between sialic acid concentrations and the haemostatic system in the elderly. $\operatorname{Br}$ Med J, 306 : 1650-1651, 1993 